\title{
ASPECTOS ÉTICOS E JURÍDICOS DO ABORTO
}

\section{Ethical and legal aspects of the abortion}

\author{
Mauro Cabrera Ambros ${ }^{l}$, Anderson Recchia ${ }^{2}$, Jeferson Ambros Recchia ${ }^{3}$
}

\begin{abstract}
RESUMO
O objetivo deste trabalho teve por finalidade realizar um estudo atualizado sobre o aborto, em seus aspectos éticos e jurídicos. Para tanto, foi pesquisada a legislação brasileira sobre este tema, bem como a de outros países. Também foram analisados os aspectos médico-legais e éticos relativos ao aborto. Foram consultadas várias obras de Medicina Legal, Direito Penal e Ética Médica, devidamente mencionados na bibliografia do presente trabalho.
\end{abstract}

Palavras-chave: aborto, legislação, ética

\section{SUMMARY}

The aim of this work was to perform an up-to-date study about the ethical and forensic aspects of abortion. To accomplish that, the Brazilian law about this subject as well the legislation of several other countries were investigated. The legal and ethical aspects concerning the abortion were equally analyzed. The search was performed in diverse reports of Forensic Medicine, Penal Law and Medical Ethics, which are referred to at the article references.

Key words: abortion

\section{INTRODUÇÃO}

O aborto é considerado um dos assuntos mais polêmicos na atualidade, pois envolve a opção pelo direito à vida. É um dos temas mais debatidos pelas diversas correntes que procuram ampliar as leis que limitam o direito à interrupção da vida no ventre materno e outras que procuram manter essas leis em relação ao assunto como elas estão. $\mathrm{O}$ aborto é proibido pela maioria das legislações dos diversos países ${ }^{1,2}$. As feministas defendem o direito da mulher e a liberdade de decidir sobre o seu próprio corpo, enquanto a Igreja Católica tem se mostrado contrária à prática do aborto em qualquer situação ${ }^{3}$.

No momento atual, esse meio terapêutico está sendo empregado de maneira confusa como anticoncepcional pelas classes sociais da população menos favorecidas e menos esclarecidas, numa tentativa de impedir o crescimento da família, e, principalmente nos casos de gravidez indesejada; no entanto, este fato já ocorre nas famílias mais abastadas há muito mais tempo ${ }^{4}$. Isto é de conhecimento público, mas todos os envolvidos, seja o praticante, como a paciente, procuram manter em sigilo, temerosos pelas sanções penais a que estão sujeitos; cientes que para a justiça, aborto é um crime doloso praticado ocasionando a interrupção da gravidez, com perda fetal ${ }^{4,5,6,7,8,9}$ e, considerando também que as consequiências advindas deste ato provocam amenorréia, infecções, tumores e perfurações do útero, além de depressão pós-menopausa, algumas com maior ou menor gravidade. Desta forma o objetivo deste trabalho teve por finalidade realizar um estudo atualizado sobre o aborto, em seus aspectos éticos e jurídicos.

\section{MATERIAL E MÉTODOS}

Os dados obtidos para a realização desse trabalho tiveram origem nas fontes citadas nas referências bibliográficas. São constituídos pela literatura especializada em termos médico-legais, jurídicos e éticos. Abrangem um extenso período de tempo que se inicia com a aprovação do Código Penal Brasileiro em 1940 e se estende até os dias atuais.

Trabalho realizado no Departamento de Clínica Médica - Centro de Ciências da Saúde (CCS) - Universidade Federal de Santa Maria (UFSM) 'Professor Adjunto do Departamento de Clínica Médica - CCS -UFSM

${ }^{2}$ Professor Titular Aposentado do Departamento de Clínica Médica - CCS - UFSM

${ }^{3}$ Médico graduado pela Universidade Federal de Santa Maria - UFSM 


\section{ABORTO: ASPECTOS ÉTICO-JURÍDICOS}

Do ponto de vista médico-legal, a terminologia apropriada para designar o mecanismo de interrupção da gravidez é abortamento, ficando aborto para designar o organismo que sai do ventre da mulher que teve sua gravidez interrompida $10,11,12,13,14,15$. Abortamento é a interrupção da relação maternoembrionária ou fetal, com a morte do produto da concepção e conseqüente expulsão ou retenção, em qualquer fase da gestação. $\mathrm{O}$ uso consagrou o termo e assim será tratado. $\mathrm{O}$ aborto pode ser espontâneo quando condições materno-fetais endógenas não permitem o prosseguimento da gestação, ou provocado quando agentes externos são aplicados intencionalmente sobre a mulher. O provocado pode ser legal (necessário e sentimental) ou criminoso (procurado, consentido e sofrido). Pela legislação brasileira os abortos social e eugênico, sendo procurados, consentidos ou sofridos, não deixam de ser criminosos ${ }^{16,17,18,19}$. O aborto eugênico não está regulamentado legalmente (já houve, inclusive, punições aos médicos que o praticaram), embora se aplique aos casos em que o feto não tem condições de vida autônoma extra-uterina.

O aborto necessário ou terapêutico é permitido por lei, pois não se pune o médico pela sua prática (C.P. art. 128, Inciso 1, art. $146 \S 3^{\circ}$ - intervenção médico-cirúrgica justificada por iminente perigo de via) e pela ética quando a lei o permite por não haver outro meio de salvar a vida da gestante. $O$ estado de necessidade deve ser referido quando: 1) a mãe apresenta perigo de vida; 2) esse perigo esteja sob a dependência direta da gravidez; 3) a interrupção da gravidez faça cessar esse perigo de vida para a mãe, 4) esse procedimento seja o único meio capaz de salvar a vida da gestante $\left.^{20,21,22,23}, 5\right)$ sempre que possível a confirmação ou concordância de no mínimo, médicos, 6) finalmente se processe conforme preceitua o Código de Ética Médica.

O aborto sentimental ou moral (C.P. art. 128 Inciso II) é permitido por lei quando a gravidez resulta de estupro, sendo autorizado por alvará judiciário ${ }^{24,25,26}$. Caso contrário, se não houver essa autorização judicial por escrito, o médico não deverá praticálo. Por que deverá assim proceder? Se houverem complicações decorrentes de manobras cirúrgicas, o médico poderá ser processado caso não tenha a autorização judicial escrita. Sendo autorizado por escrito, o aborto poderá ser praticado. Se ocorrerem complicações, a autoridade judicial será responsável. Mas segundo prescreve o Código de Ética Médica em seu artigo 28, II Capítulo - Direitos do Médico - "O médico poderá recusar-se a praticar atos médicos, permitidos por lei, que sejam contrários aos ditames de sua consciência".

É difícil a caracterização indiscutível de estupro, que é a conjunção carnal com mulher mediante violência física, psíquica ou presumida ou grave ameaça. Celeuma desde a Primeira Guerra Mundial em que soldados engravidaram mulheres de países invadidos, é assunto muito debatido, pois essas mulheres, alegando misto de revolta e de patriotismo, demandaram liceidade para abortar. Presume-se violência quando a vítima é menor de 14 anos, é alienada ou deficiente mental, não pode oferecer resistência e o agente sabe desse fato. Deve haver predomínio de forças, pois a mulher normalmente reage, pode fugir e eventualmente se defender com objeto vulnerante que esteja a seu alcance. $\mathrm{O}$ agressor tentará neutralizar a vítima mediante agressão física, sufocação, procurando segurá-la pelo quadril, deixando marcas da sua violência.

É trabalho hercúleo diferençar a gravidez resultante de estupro mediante violência psíquica ou grave ameaça de prenhez oriunda de conjunção carnal consentida ocorrendo nas grandes hecatombes por relaxamento dos costumes, míngua de víveres, comércio, como relataram pracinhas brasileiros na Seguna Guerra Mundial ${ }^{3}$. O estupro não testemunhado por terceiros, não é fácil de comprovar. A jurisprudência tem entendido que a palavra da ofendida é privilegiada. Isto pode servir de alegação gratuita para a mulher desejosa de interromper a gravidez por outros motivos, para esconder a vergonha ${ }^{3}$.

Qual a decisão do médico diante de uma solicitação desse tipo?

A legislação atualmente em vigor que vai do artigo 124 ao artigo 128 do Código Penal Brasileiro vigente, permite exceção apenas em dois casos: $1^{\circ}$ - quando não há outro meio de salvar a vida da gestante; $2^{\circ}$ - gravidez resultante de estupro.

Como citado acima, os médicos devem tomar o cuidado de sempre respaldarem as suas ações de forma a não serem incluídos em ilícito penal. A prática do aborto não deixa de ser um homicídio, embora não se puna o médico nas situações legalizadas. Devem os médicos sempre fazer um documento escrito, detalhando as razões da sua prática. Em caso de aborto terapêutico, é necessário um laudo explicando porque é praticado e no aborto moral ou sentimental é fundamental a autorização judicial escrita, embora em alguns casos, a lei permita a sua prática, bastando para isso a ocorrência policial declarando a existência de estupro. O diagnóstico de estupro é um ato médico e não pode ser feito poro profissionais não habilitados legalmente ao exercício da medicina.

Sendo ilegal o aborto no Brasil, alguns juristas o denominam de feticídio, pois é a morte do feto em qualquer fase da gestação, haja ou não expulsão. Outros juristas consideram a denominação imprópria, pois de acordo com o art. $2^{\circ}$ do Código Civil, o feto é expectativa de ser humano, possuindo expectatus de Direito e para efeitos penais considerado pessoa, bastando para isso que o concepto apresente condições de vida autônoma, ainda que precárias. O fato de dizer que não se pune os médicos não exclui a prática de um crime, pois nesse casso deve se optar por uma das vidas, ou da mãe ou do feto. De qualquer forma alguém é eliminado aquele que é a parte mais fraca e não tem escolha. $\mathrm{O}$ nome aborto terapêutico não é muito bem aplicado, pois não se conhece terapêutica em que se elimina algum ser humano. No Brasil, o direito ampara a vida desde o momento da 
fecundação e qualquer atentado contra a sua integridade está incluso em diversos artigos do Código Penal que vão desde o artigo 124 até o artigo 128, podendo as penalidades variar de 1 a 20 anos.

O Direito Repressivo Penal pune o aborto desamparado poro lei como crime, tutelando:

a) no auto-aborto, ao nascituro.

b) no aborto provocado por terceiro, ao produto da concepção e à gestante.

Desta forma, pela punição, a lei protege a mulher e o nascituro.

O crime de aborto apresenta as seguintes figuras típicas:

1) Aborto provocado pela gestante ou com seu consentimento (art. 124 do Código Penal), pena de 1-3 anos de detenção;

2) Aborto provocado por terceiro sem o consentimento da gestante (art. 125 do Código Penal), pena de 3-10 anos de reclusão;

3) Aborto provocado por terceiro com o consentimento da gestante (art. 126 do Código Penal), pena de 1-4 anos de reclusão. Parágrafo Único: Aplica-se a pena do artigo anterior se a gestante não é maior de 14 anos ou se é alienada ou débil mental ou se o consentimento é obtido mediante fraude, grave ameaça ou violência;

4) Aborto qualificado (art. 127 do Código Penal). As penas cominadas nos dois artigos anteriores são aumentadas de um terço se, em consequiência do aborto ou dos meios empregados para provocá-lo, a gestante sofre lesão corporal de natureza grave; e são duplicadas se, por qualquer dessas causas, the sobreveio a morte;

5) Aborto realizado por médico; Não se pune o aborto praticado por médico:

a) necessário ou terapêutico - art. 128, Inciso I;

b) sentimental ou humanitário - art. 128, Inciso II.

O que caracteriza os abortos entre si, em nosso Código Penal, são o agente e o consentimento da gestante ou, se ela é menor de 14 anos, alienada ou débil mental, de seu representante legal.

O agente evidentemente só pode ser o médico, único profissional legalmente habilitado à prática de atos médicos, pois se for provocado por farmacêutico, curiosas, parteiras a espécie se torna criminosa.

Caso o médico se recuse a praticar o aborto, pois de acordo com o artigo 28 do Código de Ética Médica, ele pode recusar-se alegando ditames da sua consciência, o Juiz poderá nomear profissional não médico, como enfermeira. Caberá ao Juiz a responsabilidade de qualquer complicação que ocorra. Em qualquer caso, a enfermeira-aborteira promove o deslocamento do ovo e sua morte, necessitando a paciente ser atendida posteriormente por médico para a remoção de restos placentários ou embrionários do álveo materno.

Cabe um comentário sobre quem pratica o aborto e o fato de que existem poucas punições à sua prática. Como preceitua a lei, o agente ou a gestante podem sofrer punição, mas como existe interesse mútuo, não há muitas denúncias a esse respeito pelo receio de ambas as partes temerem as sanções legais.

\section{CONCLUSÃO}

As correntes lideradas por feministas que defendem o aborto procuram despenalizá-lo, isentando de punição os seus praticantes. Baseiam-se no fato de que a mulher é dona do seu corpo e pode decidir entre a continuação ou interrupção da gravidez. Com que direito pode se permitir a sua despenalização, pois de qualquer modo a legalização do aborto não será a legalização de um crime?

\section{REFERÊNCIAS BIBLIOGRÁFICAS}

1. França GV de. Medicina Legal, $6^{\text {a }}$ Edição, Editora Guanabara Koogan, 2001, 579 pp.

2. Alcântara HR. Perícia Médica Judicial. 1 ${ }^{a}$ Edição, Editora Guanabara Dois S/A, Rio de janeiro, 1982, 367 pp.

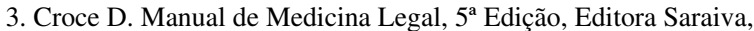
São Paulo, 2004, 839 pp.

4. Eça AJ. Roteiro de Medicina Legal, $1^{\text {a }}$ Edição, Editora Forense, Rio de Janeiro, 2003, 297 pp.

5. Almeida AF. Lições de Medicina Legal, $12^{\mathrm{a}}$ Edição, Editora Nacional, São Paulo, 1996, 614 pp.

6. Alves ES. Medicina Legal e Deontologia Médica, Editora Universitária, Paraná, 1965, 418 pp.

7. Camargo J. Aulas de Medicina Legal, Imprensa Universitária, Goiânia, 1987, 308 pp

8. Carvalho HV. Compêndio de Medicina Legal, Editora Saraiva, São Paulo, 1987, 377 pp.

9. FÁVERO F. Medicina Legal. 11 ${ }^{\mathrm{a}}$ Edição, Editora Itatiaia Ltda, Belo Horizonte, 1980, 624 pp.

10. França GV de. Comentários ao Código de Ética Médica, $4^{\mathrm{a}}$ Edição, Editora Guanabara Koogan, Rio de Janeiro - RJ, 2002, 305 pp.

11. Galvão LCC. Estudos Médicos Legais, Editora Sagra - DC Luzzatto, Porto Alegre - 1966, 305 pp.

12. Gomes H. Medicina Legal. 32 ${ }^{\mathrm{a}}$ Edição, Editora Freitas Bastos S. Rio de Janeiro. 1997, 846 pp.

13. Bevilaqua C. Código Civil dos Estados Unidos do Brasil, $5^{\text {a }}$ Edição, Editora Rio de Janeiro, 1980, 1339 pp.

14. Bittencourt CR. Tratado de Direito Penal, $3^{\mathrm{a}}$ Edição, Editora Saraiva, São Paulo, 2003, vol. 2, 555 pp.

15. Hercules HC. Medicina Legal, Texto e Atlas, Editora Atheneu, São Paulo, 2005, 714 pp.

16. Hungria N. Comentários ao Código Penal, $4^{\text {a }}$ Edição, Editora Forense, Rio de Janeiro, 1960, 442 pp.

17. Maranhão OR. Curso Básico de Medicina Legal, $8^{\mathrm{a}}$ Edição, Malheiros Editores, São Paulo, 2005, 512 pp.

18. Mirabete JF. Código Penal Interpretado, $3^{a}$ Edição, Editora 
Atlas S.A. São Paulo, 1972, 2000.

19. Pataro Medicina Legal e Prática Forense. $1^{\text {a }}$ Edição, Editora Saraiva S. A. São Paulo. 1976, 385 pp.

20. Segre M. Medicina Legal. $3^{\text {a }}$ Edição, Editora Saraiva, São Paulo. 1965, 337 pp.

21. Simonin C. Medicina Legal Judicial, 2ª Edição, Editora Jims, Barcelona. 1966, $1162 \mathrm{pp}$

22. Vasconcelos G. Lições de Medicina Legal. 1ª Edição, Editora Forense, Rio de Janeiro. 1970, 411 pp.
23. Vieira SI. Medicina Básica do Trabalho, $2^{\text {a }}$ Edição, Editora Gênesis, Curitiba, 1995, 445 pp.

24. Xavier FE. Perícia Médica no Processo Civil, Editora SagraLuzzatto, Porto Alegre, 1966, 118 pp.

Weatherall DJ. Tratado de Medicina Interna, $2^{\text {a }}$ Edição, Livraria De Rocca Ltda, São Paulo, 1992, 1400 pp.

25. Zarzuella JL. São Paulo, Editora Angelotti Ltda, 1993, $231 \mathrm{pp}$.

Endereço para correspondência:

Mauro Cabrera Ambros

Departamento de Clínica Médica

Centro de Ciências da Saúde

Universidade Federal de Santa Maria - UFSM

CEP: 97.199 - 900 - Santa Maria - RS 